\title{
A PRODUÇÃO SOBRE APRENDIZAGEM INFORMAL NAS ORGANIZAÇÕES NO BRASIL: MAPEANDO O TERRENO E RASTREANDO POSSIBILIDADES FUTURAS
}

\author{
Diogo Reatto* \\ profdiogoreatto@hotmail.com \\ Arilda Schmidt Godoy* \\ arilda-godoy@uol.com.br \\ *Universidade Presbiteriana Mackenzie - São Paulo, SP
}

http://dx.doi.org/10.1590/1413-2311.0102014.47369

Recebido em 19/03/2014

Aprovado em 24/02/2015

Disponibilizado em 01/04/2015

Avaliado pelo sistema double blind review

Revista Eletrônica de Administração

Editor: Luís Felipe Nascimento

ISSN 1413-2311 (versão on line)

Editada pela Escola de Administração da Universidade Federal do Rio Grande do Sul.

Periodicidade: Quadrimestral

Sistema requerido: Adobe Acrobat Reader.

\section{RESUMO}

A aprendizagem informal é entendida como aquela baseada na experiência intencional, mas não formalmente estruturada; induzida por um processo de reflexão crítica, ação, próatividade e criatividade; incrustada no contexto organizacional e nas práticas cotidianas. Pode ser planejada ou não, embora envolva algum grau de consciência de quem aprende. Sua relevância para o ambiente de trabalho tem sido atestada por vários autores. Este trabalho tem como objetivo identificar, descrever e analisar a produção a respeito dessa temática no Brasil, no período de 2006 a 2012. O conjunto de 21 artigos selecionados para fazer parte desta revisão reúne estudos teóricos e empíricos publicados em periódicos nacionais da área de Administração e avaliados com conceito B2 ou superior pelo WebQualis da CAPES. O estudo envolveu duas etapas. Numa primeira etapa definiram-se as fontes de dados e amostra a ser trabalhada. Uma segunda etapa consistiu na análise dos artigos a partir das seguintes dimensões: foco dos estudos (origem, tema e objetivos), nível de aprendizagem, autores referenciados, perspectivas teóricas, posicionamentos epistemológicos, tipos de pesquisa, dados de contexto da produção e principais achados. Os resultados mostram uma produção dispersa que ainda precisa ser aprimorada em relação aos arcabouços teóricos tomados como referência para o aprofundamento do tema.

Palavras-chave: Aprendizagem informal; Aprendizagem no trabalho; Aprendizagem nas organizações. 
A produção sobre aprendizagem informal nas organizações no Brasil: mapeando o terreno e rastreando possibilidades futuras

\title{
BRAZILIAN SCIENTIFIC STUDIES ABOUT INFORMAL LEARNING IN ORGANIZATIONS: MAPPING THE FIELD AND EXPLORING FUTURE POSSIBILITIES
}

\begin{abstract}
Informal learning is understood as the learning process based on intentional experience, however, not formally structured; lead by a process of critical reflection, action, proactive behavior and creativity; embedded in the social context and daily practices. It may be planned or not, although it involves some level of consciousness from the learner. Its relevancy for the workplace has been attested for several authors. This research has the objective of identifying, describing and analyzing the production concerning this subject in Brazil, from 2006 through 2012. The set of 21 articles selected to be part of this research reunite theoretical and empirical studies published in national journals of the Business Administration field, evaluated with a B2 or superior concept by the CAPES's WebQualis. The study involved two steps. The first step was to define the data and sample sources to be used in the work. The second step consisted in the analyses of articles considering the following dimensions: study focus (origin, theme and objective), learning level, referenced authors, theoretical perspective, epistemological positioning, types of research, production context data and main discoveries. The results show a scattered production that still needs to be developed in relation to theoretical drafts taken as reference for the deepening of the theme.
\end{abstract}

Keywords: Informal learning; Workplace learning; Learning in organizations.

\section{LA PRODUCCIÓN SOBRE APRENDIZAJE INFORMAL EN LAS ORGANIZACIONES EN EL BRASIL: MAPEANDO EL TERRENO Y RASTREANDO POSIBILIDADES FUTURAS}

\begin{abstract}
RESUMEN
El aprendizaje informal es aquel basado en la experiencia intencional, pero no formalmente estructurado; inducido por un proceso de reflexión crítica, acción, proactividad y creatividad; incrustado en el contexto organizacional y en las prácticas cotidianas. Puede ser planificado o no, aunque comprende cierto grado de concienciación de quien aprende. Su relevancia para el ambiente de trabajo ha sido asegurada por varios autores. Este trabajo tiene el objetivo identificar, describir y analizar la producción sobre esta temática en el Brasil, en el período de 2006 a 2012. El conjunto de 21 trabajos seleccionados para formar esta revisión reúne estudios teóricos y empíricos publicados en periódicos nacionales del área de la Administración y evaluados con calificación B2 o superior por el WebQualis de la CAPES. El estudio tuvo dos etapas. En la primera etapa se definieron las fuentes de datos y muestra a ser trabajada. En la segunda hubo el análisis de los artículos desde las siguientes dimensiones: foco del estudio (origen, tema y objetivos), nivel de aprendizaje, autores citados, perspectivas teóricas, posicionamientos epistemológicos, tipos de investigación, datos de contexto de la producción y principales conclusiones. Los resultados muestran una producción dispersa que todavía necesita ser mejorada en relación con los andamiajes teóricos tomados como referencia para la profundización del tema.
\end{abstract}

REAd | Porto Alegre - Edição 80 - № 1 - janeiro/abril 2015 - p. 57-88 
Diogo Reatto \& Arilda Schmidt Godoy

Palabras clave: Aprendizaje informal; Aprendizaje en el trabajo; Aprendizaje en las organizaciones.

\section{INTRODUÇÃO}

O conceito de Aprendizagem Informal (denominada aqui como AI) tem suas raízes nos anos 20 e 30 do século XX aparecendo nos trabalhos do filósofo da educação John Dewey, do psicólogo Kurt Lewin e de Mary Parker Follet a qual se formou em filosofia, história e ciência política, destacando-se especialmente por seus trabalhos na área da administração. Para esses autores, a aprendizagem acontece pelo histórico das experiências individuais vivenciadas, pela reflexão a respeito daquilo que é aprendido ocorrendo a partir das interações dos indivíduos com o seu meio ambiente (CONLON, 2004; MARSICK; WATKINS, 2001). Contudo, o termo AI não emergiu até a década de 50 do século passado, quando Malcolm Knowles - considerado o pai da Andragogia - publicou sua obra "Educação Informal de Adultos". As primeiras revisões sobre pesquisas em AI surgiram na década de 90 com autores como Marsick e Watkins e Garrick (MARSICK; WATKINS, 2001), as quais relacionavam o conceito de AI com termos como aprendizagem en passant, aprendizagem incidental e não formal, aprendizagem experiencial, aprendizagem autodirigida, aprendizagem na ação, reflexão na ação, reflexão crítica e aprendizagem transformativa, conhecimento tácito e aprendizagem situada. Tanto Marsick e Watkins (2001), na literatura internacional, quanto Antonello (2011), na literatura nacional, alertam que, embora todos esses termos estejam relacionados com a AI, nem sempre podem ser considerados sinônimos dela.

Por isso, este estudo se pauta na caracterização de Marsick e Watkins (2001) e Watkins e Marsick (1992) sobre o que se considera AI: aprendizagem baseada numa experiência intencional, mas não formalmente estruturada; induzida por um processo de reflexão crítica, pela ação, pela pró-atividade e pela criatividade; incrustada no contexto organizacional e nas práticas cotidianas. Pode ser planejada ou não, no entanto envolve algum grau de consciência de quem está aprendendo.

A relevância da AI nos locais de trabalho das organizações e para os estudos de Aprendizagem Organizacional tem sido sistematicamente atestada. Livingstone, em 2000, baseando-se em pesquisas realizadas no Canadá, destacou que mais de $70 \%$ da aprendizagem que ocorre nos locais de trabalho é de natureza informal e Eraut (2011), em recente publicação que traz resultados de duas pesquisas patrocinadas pelo ESRC (Economic \& Social Research Council) do Reino Unido afirma que, para esta amostragem, as atividades informais desenvolvidas no trabalho foram responsáveis por cerca de 70 a $90 \%$ daquilo que

REAd | Porto Alegre - Edição 80 - № 1 - janeiro/abril 2015 - p. 57-88 
A produção sobre aprendizagem informal nas organizações no Brasil: mapeando o terreno e rastreando possibilidades futuras

foi aprendido.

No Brasil, não foram encontradas revisões recentes que tratassem da temática com foco na produção em periódicos, abarcando todas as dimensões aqui examinadas. Dessa forma, considera-se que este trabalho representa uma contribuição a mais para a constituição desse campo de estudos. Tem como objetivo identificar, descrever e analisar a produção no campo de estudos de Aprendizagem Informal nas organizações no Brasil, no período que se estende de 2006 a 2012. Como corpus de análise, consideram-se artigos nacionais publicados em periódicos da área da Administração, classificados pela CAPES como B2 ou superior.

A primeira seção do artigo embasa teoricamente a importância dos estudos de AI para as organizações e para um novo entendimento do campo da Aprendizagem Organizacional. Na sequência, a seção 2 apresenta o percurso metodológico e as dimensões envolvidas na organização das informações dos artigos examinados. A apresentação e a análise dos resultados são expostas na seção 3. A reflexão trazida pelos autores para fechamento do artigo (seção 4) procura explicitar o processo interativo que se desenvolveu entre os pesquisadores e a elaboração do conhecimento gerado a partir dos resultados encontrados. Buscou-se aqui alcançar uma melhor apreciação do conhecimento produzido trazendo as contradições teóricas que cercam este campo, examinando tanto a natureza dos fenômenos focados nessa produção quanto as várias lentes metodológicas que os pesquisadores usaram ao investigá-los.

Acredita-se que este trabalho contribui no mapeamento da produção científica sobre AI nas organizações e no incentivo à reflexão a respeito da relevância dessa temática dentro do campo da Aprendizagem Organizacional, seus métodos de estudo, seus desafios e limites.

\section{A RELEVÂNCIA DA APRENDIZAGEM INFORMAL NO LOCAL DE TRABALHO PARA A APRENDIZAGEM ORGANIZACIONAL}

Aprendizagem e trabalho eram conceitos que sempre costumaram ser vistos como separados, em que o trabalho servia para a produção de bens para a sobrevivência, enquanto que a aprendizagem se relacionava à educação formal necessária para entrar no mercado de trabalho. No entanto, para enfrentar a nova realidade de que o conhecimento é o recurso basilar de uma organização atualmente, o local de trabalho tem recebido o reconhecimento como um ambiente poderoso para prover os indivíduos de uma aprendizagem válida, capaz de prepará-los para enfrentar uma economia globalizada e, as organizações, por sua vez, uma demanda crescente de trabalhadores do conhecimento dentro de uma sociedade de alto conhecimento tecnológico (BOUD; GARRICK, 1998).

REAd | Porto Alegre - Edição 80 - No 1 - janeiro/abril 2015 - p. 57-88 
Devido a esse caráter altamente mutável do trabalho na contemporaneidade, as formas pelas quais os indivíduos e as organizações percebem a aprendizagem podem ser muito diferentes (GERBER, 2006; LE CLUS, 2011), o que interfere, principalmente, no "o que" as pessoas aprendem no trabalho. Por isso que as lentes da Aprendizagem Organizacional no local de trabalho têm repousado sobre como as pessoas aprendem no trabalho, que uso elas fazem dessa aprendizagem e quais são os impactos desse aprendizado na vida dos indivíduos, de seus colegas e na organização como um todo (GERBER, 2006).

Num conceito abrangente formado pela citação de diversos autores, para Le Clus (2011, p. 357) a aprendizagem no local de trabalho:

pode ser descrita como situada no contexto da prática social (Lave\&Wanger 1991), na qual o cenário do trabalho fornece uma oportunidade de trabalhadores adquirirem conhecimento que conectem teoria e prática de uma forma realista e eficiente (Billet 1996). Aprendizagem no local de trabalho inclui aprendizagem baseada na experiência, aprendizagem informal e incidental (Marsick\&Watkins 2001, Marsick\&Volpe 1999, Foley 1999, Hager\&Halliday 2006), aprendizagem autodirigida (Foley 1999) bem como aprendizagem organizacional formal (Senge 1990).

No ambiente de trabalho há possibilidades potenciais para que a aprendizagem se desenvolva, sobretudo, informalmente, pois como essa aprendizagem acontece por meio das oportunidades que estão integradas nas rotinas e práticas de trabalho cotidianas, há maior chance de a AI ocorrer com maior frequência do que a formal. O aprender informalmente está relacionado às experiências espontâneas de vida do indivíduo em situações cotidianas como o aprender na escola, na família, com os amigos. Contudo, a AI, de acordo com Garrick (1998), caracteriza-se como um dos discursos vigentes a respeito da aprendizagem baseada no trabalho e da aprendizagem que ocorre a partir da experiência do indivíduo. Independentemente da abordagem sobre a qual a AI possa ser vista e estudada, a AI no local de trabalho deve sustentar-se na concepção de aprendizagem como processo, por meio da qual as pessoas, individualmente e em associação com as demais, empenham-se num encontro direto, pessoal e, então, propositalmente, refletem sobre ele, validam, transformam, dão significado e procuram integrar seus diferentes tipos de conhecimento (GARRICK, 1998).

Os resultados de diversos estudos encontrados na literatura internacional reconhecem que o ambiente de trabalho tem sido legitimado para a aprendizagem de novas habilidades e conhecimentos que permitam aos indivíduos uma melhor participação nas atividades do dia-adia (LE CLUS, 2011).

Eraut (2011), em publicação que traz resultados de duas pesquisas patrocinadas pelo ESRC (Economic \& Social Research Council) do Reino Unido, concluiu que, a partir do REAd | Porto Alegre - Edição 80 - No 1 - janeiro/abril 2015 - p. 57-88 
A produção sobre aprendizagem informal nas organizações no Brasil: mapeando o terreno e rastreando possibilidades futuras

momento em que as organizações dão condições favoráveis à aprendizagem, a WPL (workplace learning) pode ser melhorada em diversos processos de trabalho. Eraut (2011) constatou que trabalhar ao lado de um colega e compartilhar as mesmas tarefas com ele por um tempo permite aprender fazendo perguntas e recebendo devolutivas dessas atividades compartilhadas. Isso permite compreender como o indivíduo percebe a situação, monitora-a e toma decisões. Para Eraut (2011), essas ações são tácitas e difíceis de serem explicadas, principalmente quando envolvem profissionais de diferentes especialidades.

Quando se trata de como as pessoas aprendem no trabalho, reconhece-se que, em situações e em diferentes tipos de trabalho, as pessoas têm o potencial de aprender diferentemente uma das outras (HAGER, 2012). Os resultados de pesquisas empíricas realizadas entre trabalhadores de especialidades, ambientes de trabalho e níveis hierárquicos diferentes mostraram que todos os indivíduos usam formas de aprender que não lhes foram oferecidas por suas experiências formais de aprendizagem, nem mesmo antes de terem seus empregos atuais ou ainda até mesmo durante o emprego (GERBER, 2006).

Ao revisar 39 estudos qualitativos sobre AI, Marsick e Yates (2012) encontraram que as experiências de aprendizagem informal estavam integradas ao trabalho e às rotinas diárias, cujo gatilho geralmente era um choque, um desafio ou uma situação de surpresa. Também, que a aprendizagem aconteceu por meio de solução de problemas, frequentemente com ajuda de terceiros, o que lhes permitiu afirmar que a conversa, as interações sociais, a colaboração, os relacionamentos e as práticas são o coração da AI.

Da mesma forma, Cunningham e Hillier (2013) revisaram a literatura com o objetivo primário de identificar como os indivíduos aprendem nas organizações. Os achados estão calcados numa aprendizagem baseada nas atividades e nos processos informais de dar e receber mentorias, na construção e manutenção de relacionamentos com colegas mais experientes e em desafios em novas funções ou atribuições.

Resultados de outra pesquisa de Cunningham e Hillier (2013), desta vez empírica, com 84 supervisores de departamentos, somam à lista de revisão teórica de como se aprende informalmente no local de trabalho processos como quando o indivíduo abraça mais responsabilidades do que aquelas previstas em seu cargo; quando desenvolve uma rede de contatos de aprendizagem e compartilha seus conhecimentos e descobertas com essa rede; e quando constrói relacionamentos positivos com colegas em seu local de trabalho.

Essas formas de aprender, informais em suas abordagens, sugerem que são os trabalhadores e não os que os treinam que deveriam ter o controle das maneiras pelas quais 
eles aprendem no trabalho (HAGER, 2012). É por meio da aprendizagem informal no local de trabalho que os trabalhadores-aprendizes adquirem atitudes, valores, habilidades e conhecimento como parte de suas rotinas diárias (LE CLUS, 2011).

Assim, tem-se que aprender é um processo contínuo diário, entrelaçado e inseparável do aprender diariamente no trabalho. Dentro dessa perspectiva, aprender é parte da existência humana e do desenvolvimento do trabalhador no cenário social do trabalho e da organização. Logo, é natural e potencial que a AI ocorra muito mais frequentemente que outras formas de aprendizagem, pois a AI emerge das atividades cotidianas no local de trabalho (LE CLUS, 2011; HAGER, 2012).

Portanto, adotar formas que apoiem essa aprendizagem é importante, contudo é mais relevante ainda a construção de significados, de imagens de mundo, o desenvolvimento de identidades, de práticas coletivas e de novas perspectivas de se entender a vida, o trabalho e sua aprendizagem nas organizações (ANTONACOPOULOU, 2006).

\title{
2 PERCURSO METODOLÓGICO
}

Segundo Noronha e Ferreira (2000, p.191)

\begin{abstract}
Trabalhos de revisão são estudos que analisam a produção bibliográfica em determinada área temática, dentro de um recorte de tempo, fornecendo uma visão geral ou um relatório do estado-da-arte sobre um tópico específico, evidenciando novas ideias, métodos, subtemas que têm recebido maior ou menor ênfase na literatura especializada. Assim, a consulta a um trabalho de revisão propicia ao pesquisador tomar conhecimento, em uma única fonte, do que ocorreu ou está ocorrendo periodicamente no campo estudado.
\end{abstract}

Os trabalhos de revisão, com seu alto teor analítico, têm sido valorizados pela contribuição que podem proporcionar ao desenvolvimento do conhecimento científico na medida em que compactam e comparam o conhecimento disperso em várias fontes, identificam novas especializações e áreas de interesse, direcionam esforços de pesquisas futuras, constituem fonte de consulta tanto para pesquisadores experientes quanto para novatos, dão suporte à busca bibliográfica, informam sobre campos correlatos e áreas multidisciplinares, oferecem feedback pela avaliação e crítica que fazem da produção analisada (NORONHA; FERREIRA, 2000). Podem ser desenvolvidos como respaldo teórico para dissertações, teses e projetos de pesquisa ou serem realizadas como um fim em si mesmas, efetuando um trabalho analítico e crítico no qual o revisor não só identifica e descreve os trabalhos encontrados, mas também julga seu valor e contribuição. O artigo aqui relatado está alinhado com a segunda preocupação.

REAd | Porto Alegre - Edição 80 - No 1 - janeiro/abril 2015 - p. 57-88 
A produção sobre aprendizagem informal nas organizações no Brasil: mapeando o terreno e rastreando possibilidades futuras

Para isso, a metodologia que orientou o trabalho aqui apresentado consta de três etapas fundamentais, inspiradas na revisão desenvolvida por Godoy e Antonello (2011) a respeito do tema da aprendizagem organizacional no Brasil. Numa primeira etapa definiram-se as fontes de dados e amostra a ser trabalhada. Uma segunda etapa consistiu no planejamento do itinerário analítico a ser seguido, com decisões a respeito das dimensões que orientariam esse trajeto, assim como das formas de codificação e registro dos dados a serem adotadas. A terceira etapa consistiu na descrição e apresentação dos resultados obtidos.

O cumprimento da primeira etapa envolveu a decisão de que o conjunto de artigos selecionados para fazer parte desta revisão reuniria estudos teóricos e empíricos, publicados em periódicos nacionais, no período de 2006 a 2012. Os periódicos foram selecionados dentre os apresentados pelo WebQualis da CAPES - Coordenação de Aperfeiçoamento de Pessoal de Nível Superior - da área de Administração, avaliados com conceito B2 ou superior, no ano de 2013. Desse conjunto de periódicos foram excluídos os da área de Ciências Contábeis e de Turismo e também aqueles que não tinham relação direta com o tema "aprendizagem informal nas organizações", como os de agronegócios, economia, engenharia da produção, custos, enfermagem, entre outros. A lista final contou com 23 periódicos. Num primeiro momento realizou-se o levantamento dos artigos tendo como critério a busca em títulos, resumos e palavras-chave (aqui consideradas aquelas que tivessem a mesma relação de sinonímia com AI, tais como: aprendizagem experiencial, aprendizagem na ação ou na prática, aprendizagem no trabalho, improvisação, aprendizagem situada, experiência, reflexão). Num segundo momento, foi feita a leitura dos artigos selecionados para que se descartassem aqueles que não contemplavam a temática AI nas organizações. Assim, dos 23 periódicos consultados, identificou-se que 8 trouxeram artigos sobre o tema (Quadro 1). No total, 21 artigos constituíram o conjunto a ser analisado.

Quadro 1 - Número de artigos utilizados na revisão

\begin{tabular}{|l|c|c|c|c|c|c|c|c|}
\hline \multicolumn{1}{|c|}{ Periódico } & \multicolumn{9}{c|}{ Número de artigos } \\
\cline { 2 - 9 } & $\mathbf{2 0 0 6}$ & $\mathbf{2 0 0 7}$ & $\mathbf{2 0 0 8}$ & $\mathbf{2 0 0 9}$ & $\mathbf{2 0 1 0}$ & $\mathbf{2 0 1 1}$ & $\mathbf{2 0 1 2}$ & Total \\
\hline Revista de Administração Mackenzie (RAM) & 0 & 0 & 1 & 0 & 1 & 4 & 0 & $\mathbf{6}$ \\
\hline Revista de Administração Contemporânea (RAC) & 1 & 0 & 0 & 1 & 1 & 1 & 0 & $\mathbf{4}$ \\
\hline Revista Organizações e Sociedade (O\&S) & 1 & 0 & 1 & 0 & 0 & 1 & 0 & $\mathbf{3}$ \\
\hline Brazilian Administration Review (BAR) & 0 & 0 & 0 & 0 & 1 & 0 & 1 & $\mathbf{2}$ \\
\hline Revista Alcance & 1 & 0 & 1 & 0 & 0 & 0 & 0 & $\mathbf{2}$ \\
\hline Cadernos EBAPE.BR/FGV & 0 & 1 & 0 & 0 & 0 & 1 & 0 & $\mathbf{2}$ \\
\hline Revista de Administração Pública (RAP) & 0 & 0 & 0 & 0 & 0 & 0 & 1 & $\mathbf{1}$ \\
\hline Revista Perspectivas Contemporâneas & 0 & 0 & 0 & 0 & 0 & 0 & 1 & $\mathbf{1}$ \\
\hline TOTAL & 3 & 1 & 3 & 1 & 3 & 7 & 3 & $\mathbf{2 1}$ \\
\hline
\end{tabular}

Fonte: Dados coletados pelos autores (2013).

Na segunda etapa foram definidas as dimensões analíticas que compuseram o template

REAd | Porto Alegre - Edição 80 - No 1 - janeiro/abril 2015 - p. 57-88 
Diogo Reatto \& Arilda Schmidt Godoy

utilizado durante o processo de captação, codificação e registro das informações presentes em cada um dos artigos, a saber: foco dos estudos (origem, tema e objetivos), nível de aprendizagem, autores nacionais e internacionais referenciados, perspectivas teóricas de aprendizagem, posicionamentos epistemológicos adotados, tipos de pesquisa, dados de contexto da produção e principais achados e resultados. Esse template foi adaptado a partir das dimensões analíticas utilizadas por Godoy e Antonello (2011), as quais estão explicitadas no Quadro 2.

Quadro 2 - Dimensões analíticas do template utilizado

\begin{tabular}{|ll|}
\hline \multicolumn{1}{|c|}{ Dimensões Analíticas } \\
\hline 1. & Focos de Investigação \\
\hline & Título do documento \\
\hline & Tema de estudo \\
\hline & Questões de pesquisa \\
\hline & Objetivos dos estudos \\
\hline & Palavras-chave \\
\hline 2. & Conceituação de Aprendizagem Informal \\
\hline 3. & Bases teóricas \\
\hline 4. & Níveis de Aprendizagem Informal \\
\hline 5. & Análise das perspectivas teóricas de Aprendizagem Informal \\
\hline & Baseada em Easterby-Smith, Lyles, (2003) Dierkes et al. (2001): \\
& Psicológica (experiencial, comportamental, social e aplicada), Sociológica, \\
\hline 6. & Antropológica, Política, Ciência da Administração, Econômica. \\
\hline 7. & Natureza do estudo \\
\hline 8. & Tipos de pesquisa \\
\hline 9. & Amostra e/ou sujeitos pesquisados \\
\hline 10. & Principais achados e resultados \\
\hline 11. & Dados de contexto (pesquisadores e grupos de pesquisa) \\
\hline
\end{tabular}

Fonte: Elaborado pelos autores (2013).

O registro dessas informações foi realizado numa planilha Excel por um dos pesquisadores, sendo posteriormente revisada pelo outro, por meio de um processo de intensa interação visando a verificar erros, dirimir dúvidas e tomar decisões a respeito do preenchimento do template.

A terceira etapa consistiu na escrita e interpretação dos resultados encontrados, organizada a partir das dimensões previamente definidas e que compõem a seção a seguir.

Finalmente, destaca-se a postura de reflexividade que os pesquisadores adotaram durante todo o processo investigativo. Schwandt (2001, p. 224) esclarece que o termo reflexividade "usado no sentido metodológico refere-se ao processo de autorreflexão crítica dos nossos próprios vieses, predisposições teóricas, preferências, e assim por diante”. Esta espécie de autoinspeção é salutar em qualquer tipo de investigação, e aqueles que desenvolvem pesquisas de campo frequentemente são encorajados a explorar suas atitudes, estados de espírito, ideias e sentimentos em notas pessoais que ficam registradas nos diários 
A produção sobre aprendizagem informal nas organizações no Brasil: mapeando o terreno e rastreando possibilidades futuras

de campo. No caso do trabalho de revisão aqui relatado a reflexividade ocorreu por meio dos sucessivos diálogos estabelecidos entre os dois pesquisadores durante as etapas dois e três do estudo realizado. Reflexividade, no sentido metodológico, também aponta para o fato de que o investigador é parte do ambiente, contexto e dos fenômenos sociais que procura compreender. Pode ainda ser entendida como um meio de inspecionar criticamente todo o processo da pesquisa, estando aqui associada à validade dos relatos obtidos.

\section{APRESENTAÇÃO E ANÁLISE DOS RESULTADOS}

Os resultados encontrados estão expostos a partir das dimensões analíticas que, no entanto, foram examinadas de forma articulada e integrada, sem perder de vista o contexto de sua produção.

\subsection{Focos de investigação}

O foco dos estudos foi detectado considerando-se os seguintes aspectos: questão de pesquisa declarada pelo(s) autor(es) do artigo, títulos, objetivos, temas tratados no artigo e palavras-chave. No Quadro 3 apresentam-se os 8 agrupamentos (categorias), que emergiram da leitura atenta dos aspectos acima apontados, nos quais se classificaram os estudos. As categorias não são excludentes, logo os estudos podem pertencer a mais de uma categoria.

Quadro 3 - Focos de investigação

\begin{tabular}{|l|l|c|}
\hline \multicolumn{1}{|c|}{ Categoria } & \multicolumn{1}{|c|}{ Total } \\
\hline $\begin{array}{l}\text { Processos de } \\
\text { aprendizagem informal }\end{array}$ & $\begin{array}{l}\text { Abarcam estudos que buscam compreender que sentido os indivíduos dão ao } \\
\text { seu trabalho, em que medida as organizações apóiam a aprendizagem informal } \\
\text { e as consequentes formas pelas quais aprendem. }\end{array}$ & 15 \\
\hline $\begin{array}{l}\text { Abordagens de } \\
\text { aprendizagem informal }\end{array}$ & $\begin{array}{l}\text { Abrange estudos cuja preocupação é identificar e descrever os processos de } \\
\text { aprendizagem sob uma ou mais abordagens da aprendizagem informal, entre } \\
\text { elas: aprendizagem incidental, situada, experiencial, pela experiência, } \\
\text { aprendizagem de adultos, no trabalho, na ação, e reflexão na aprendizagem. }\end{array}$ & 12 \\
\hline $\begin{array}{l}\text { Aprendizagem } \\
\text { gerencial }\end{array}$ & $\begin{array}{l}\text { Estudos teóricos e empíricos que discutem e investigam o processo de } \\
\text { aprendizagem informal de indivíduos que desenvolvem funções gerenciais, } \\
\text { visando a identificar como os gerentes aprendem. Predominam os estudos que } \\
\text { consideram o ambiente e o contexto como mediadores dessa aprendizagem. }\end{array}$ & 10 \\
\hline $\begin{array}{l}\text { Aprendizagem não } \\
\text { gerencial }\end{array}$ & $\begin{array}{l}\text { Estudos teóricos e empíricos que visam a discutir e investigar os processos de } \\
\text { aprendizagem de indivíduos que não ocupam cargos de gerência e não } \\
\text { desenvolvem funções gerenciais. Os sujeitos de pesquisa estão alocados em } \\
\text { diversos tipos de organizações como bares, restaurantes, instituições de ensino } \\
\text { e hospitais. }\end{array}$ & 08 \\
\hline $\begin{array}{l}\text { Aprendizagem e o } \\
\text { contexto social }\end{array}$ & $\begin{array}{l}\text { Estudos que declararam sua preocupação com o contexto social nos processos } \\
\text { de aprendizagem e se dispuseram a considerar as diversas interações sociais } \\
\text { do indivíduo no provimento da aprendizagem. }\end{array}$ & 07 \\
\hline $\begin{array}{l}\text { Métodos de pesquisa e } \\
\text { estado da arte }\end{array}$ & $\begin{array}{l}\text { Estudos que têm como objetivos centrais descrever, analisar e discutir novas } \\
\text { formas de se abordar e pesquisar a aprendizagem informal. }\end{array}$ & 07 \\
\hline $\begin{array}{l}\text { Fatores incentivadores } \\
\text { e que dificultam a } \\
\text { aprendizagem }\end{array}$ & $\begin{array}{l}\text { Aqui estão agrupados os artigos que objetivam descrever, analisar e discutir } \\
\text { fatores e/ou estabelecer relação entre variáveis que condicionam, facilitam ou } \\
\text { dificultam os processos de aprendizagem informal. }\end{array}$ & 02 \\
\hline Emoções & Estudos que questionam a função e o impacto dos sentimentos dos indivíduos & 01 \\
\hline
\end{tabular}




\begin{tabular}{|l|l|l|}
\hline & $\begin{array}{l}\text { em determinado contexto ou quando submetidos a certas situações de trabalho } \\
\text { e sua relação com a aprendizagem informal. }\end{array}$ & \\
\hline
\end{tabular}
Fonte: Dados coletados pelos autores (2013).

A partir do quadro apresentado acima, observa-se que dos 21 artigos analisados, 15 preocuparam-se em compreender como os indivíduos aprendem nas organizações e a identificar quais atividades, processos e dinâmicas promovem a AI neste contexto. Diferentemente dos achados de Godoy e Antonello (2011), que focaram a aprendizagem organizacional, os estudos de AI cuja preocupação estava nos fatores facilitadores ou obstáculos para os processos de aprendizagem nas organizações foram minoria (2), sendo este objetivo secundário e não principal.

Foram detectados 12 estudos que declaram sob qual abordagem vão tratar a $\mathrm{AI}$, de acordo com os inúmeros sinônimos sugeridos por Marsick e Watkins (2001). Esses estudos também se preocuparam em identificar os processos de AI dentro da abordagem escolhida.

Como em Godoy e Antonello (2011), ainda se nota grande preferência (10) em pesquisar o processo de AI de gerentes. Contudo, o campo aponta mudanças ao direcionar seu olhar também para o estudo dos processos de AI daqueles indivíduos que não desenvolvem funções gerenciais (8). Ambas as categorias possuem estudos (7) que ressaltam a preocupação com o contexto social no qual os indivíduos estão inseridos, como esses indivíduos constroem seus relacionamentos e estes interferem nos processos de AI.

Sete trabalhos categorizados em métodos de pesquisa e estado da arte são estudos que sugerem um novo olhar para o tema da AI por meio de novas metodologias de pesquisa, metáforas, comparações entre teorias e visões alternativas que tragam novas possibilidades para a compreensão desse fenômeno.

Finalmente, encontrou-se um único estudo que se preocupa em identificar quais e como os sentimentos e as experiências emocionais impactam os processos de AI de um profissional.

\subsection{Conceituação de Aprendizagem Informal}

Esta seção resgata os conceitos de AI apresentados e tomados como referência nos estudos analisados.

O termo AI foi citado nas palavras-chave de somente dois artigos e quatro artigos conceituaram AI em seu referencial teórico. Todos os demais referiram-se e conceituaram AI por meio dos termos a ela associados, a saber: aprendizagem de adultos (2); aprendizagem na prática (8); saberes práticos (8); aprendizagem situada (4); aprendizagem experiencial (5); 
A produção sobre aprendizagem informal nas organizações no Brasil: mapeando o terreno e rastreando possibilidades futuras

aprendizagem no local de trabalho (3); aprendizagem na ação (1); improvisação (1) e estratégias de aprendizagem no trabalho (1).

Os pesquisadores de dois estudos declararam sua preocupação em não conceituar AI porque acreditam que aprendizagem formal e informal não são áreas de conhecimento concorrentes mas que se complementam, pois em espaços formais é possível se aprender informalmente. Por isso, seria importante não compará-las ou contrapô-las, senão integrá-las.

Os artigos que optaram por definir AI fizeram-no baseado somente em uma referência: Marsick e Watkins (2001) foram lembrados em dois estudos, seguidos de Conlon (2004) e Day (1998). Os conceitos usados pelos pesquisadores estão apresentados no Quadro 4.

Quadro 4 - Conceitos de Aprendizagem Informal Declarados

\begin{tabular}{|l|l|}
\hline \multicolumn{1}{|c|}{ Autores } & \multicolumn{1}{c|}{ Conceito de Aprendizagem Informal } \\
\hline $\begin{array}{l}\text { Marsick e Watkins } \\
(2001)\end{array}$ & $\begin{array}{l}\text { "Aprendizagem informal é definida como um subproduto de algumas atividades, como } \\
\text { cumprimento de tarefas, interação interpessoal, sentir a cultura organizacional, } \\
\text { experimentação por tentativa e erro, ou até mesmo da aprendizagem formal, e pode ser } \\
\text { deliberadamente encorajada por uma organização ou também pode ocorrer mesmo que } \\
\text { o ambiente não seja altamente propício para tal". } \\
\text { "A aprendizagem informal pode ocorrer a partir de experiências formalmente } \\
\text { estruturadas, ou seja, que ela pode ser planejada ou não [...], mesmo quando não é } \\
\text { planejada, a aprendizagem informal costuma envolver algum grau de consciência do } \\
\text { aprendiz, sendo possível encontrá-la, inclusive, em processos formais de ensino". }\end{array}$ \\
$\begin{array}{l}\text { "Aprendizagem informal se refere a oportunidades naturais que surgem no cotidiano, } \\
\text { onde a própria pessoa controla seu processo de aprendizagem. Além disso, caracteriza- } \\
\text { se como predominantemente experiencial, prática e não-institucional”. }\end{array}$ \\
\hline $\begin{array}{l}\text { "A aprendizagem informal é pontual e específica das necessidades do indivíduo; } \\
\text { portanto, constitui evento altamente relevante para ele. Partindo do pressuposto de que } \\
\text { existem discrepâncias entre o que os indivíduos sabem e o que eles devem saber, a } \\
\text { aprendizagem informal proporciona um aprendizado incremental do que deve ser } \\
\text { aprendido e sabido". }\end{array}$ \\
\hline Day (1998)
\end{tabular}

Fonte: Dados coletados pelos autores (2013).

\subsection{Bases teóricas}

Esta seção apresenta os principais autores que nortearam os artigos analisados.

A identificação dos autores limitou-se às referências citadas no referencial teórico e resgatadas na discussão dos resultados e nas considerações finais de cada estudo. Inicialmente, separaram-se as principais referências em autores nacionais e internacionais. $\mathrm{O}$ Quadro 5 apresenta a frequência de aparecimento dos autores internacionais e seus respectivos livros e/ou artigos empregados nos estudos brasileiros. Exatamente 138 autores diferentes foram mencionados como primeiro autor, a maioria deles uma vez, perfazendo um total de 314 referências. Para a exposição no quadro, consideraram-se somente aqueles com três ou mais referências às suas obras.

REAd | Porto Alegre - Edição 80 - № 1 - janeiro/abril 2015 - p. 57-88 
Diogo Reatto \& Arilda Schmidt Godoy

Quadro 5 - Literatura internacional e autores referenciados nos estudos

\begin{tabular}{|c|c|c|}
\hline $\begin{array}{c}\text { Autores } \\
\text { internacionais }\end{array}$ & Obras mais referenciadas & $\begin{array}{l}\text { Frequênci } \\
\text { a }\end{array}$ \\
\hline $\begin{array}{l}\text { Gherardi, S.; } \\
\text { Nicolini, D. }\end{array}$ & $\begin{array}{l}\text { - The sociological foundations of organizational learning. In M. Dierkes, A. } \\
\text { Berthoin Antal, J. Child, \& I. Nonaka (Orgs.), The handbook of } \\
\text { organizational learning and knowledge. Oxford: Oxford University Press, } \\
\text { 2001. p. 35-60 } \\
\text { - Toward a social understanding of how people learn in organizations. } \\
\text { Management Learning, v. } 29, \text { n. 3, p. } 273-297,1998 \text {. } \\
\text { - Knowing in organizations: a practice-based approach. London: Sharpe, } \\
\text { 2003. }\end{array}$ & 21 \\
\hline $\begin{array}{l}\text { Argyris, C.; } \\
\text { Schon, D. A. }\end{array}$ & $\begin{array}{l}\text { - Theory and practice: increasing professional effectiveness. San Francisco: } \\
\text { Jossey-Bass Publishers, } 1974 \text {. } \\
\text { - Organizational Learning: a theory of action perspective. Reading, } \\
\text { Massachusetts: Addison- Wesley,1978. }\end{array}$ & 15 \\
\hline Kolb, D. A. & $\begin{array}{l}\text { - Experimental learning: experience as the source of learning. New Jersey: } \\
\text { Prentice-Hall, } 1984 .\end{array}$ & 15 \\
\hline Schon, D. A. & - The reflective practitioner. New York, NY: Basic Books, 1983. & 12 \\
\hline $\begin{array}{l}\text { Lave, J.; Wenger, } \\
\text { E. }\end{array}$ & $\begin{array}{l}\text { - Situated learning: legitimate peripheral participation. New York: } \\
\text { Cambridge University Press, 1991. }\end{array}$ & 12 \\
\hline $\begin{array}{l}\text { Antonacopoulou, } \\
\text { E. P. }\end{array}$ & $\begin{array}{l}\text { - Emotion, learning and organizational change: towards and integration of } \\
\text { psychoanalytic and other perspectives. Journal of Organizational Change } \\
\text { Management, Special Issue on 'Organizational Change and } \\
\text { Psychodynamics', v. } 14, \text { n. 5, p. 435-451, } 2001 \text {. }\end{array}$ & 10 \\
\hline $\begin{array}{l}\text { Easterby-Smith, } \\
\text { M.; Araujo, L. }\end{array}$ & $\begin{array}{l}\text { - Aprendizagem organizacional: oportunidades e debates atuais. In: } \\
\text { EASTERBY-SMITH, M.; BURGOYNE, J.; ARAUJO, L. (coords.). } \\
\text { Aprendizagem organizacional e organização de aprendizagem: } \\
\text { desenvolvimento na teoria e na prática. São Paulo: Atlas, 2001. } \\
\text { - Organizational learning: diverging communities of practice. Management } \\
\text { Learning, v. 29, n.3, p. 259-272, } 1998 \text {. }\end{array}$ & 10 \\
\hline Dewey, J. & - Educação e Experiência. 3. ed. São Paulo: Ed. Nacional, 1979. & 09 \\
\hline $\begin{array}{l}\text { Marsick, V.; } \\
\text { Watkins, K. E. }\end{array}$ & $\begin{array}{l}\text { - Experience-based learning: executive learning outside the classroom. } \\
\text { Journal of Management Development, v. 9, n. 4, p. 50-60, 1990. } \\
\text { - Toward a theory of informal and incidental learning in organizations. } \\
\text { International Journal of Lifelong Education, v. } 11, \text { n. 4, p. } 287-300,1992 \text {. }\end{array}$ & 09 \\
\hline Wenger, E. & $\begin{array}{l}\text { - Communities of practice: learning, meaning, and identity. New York: } \\
\text { Cambridge University Press, } 1998 .\end{array}$ & 08 \\
\hline Mezirow, J. & $\begin{array}{l}\text { - Transformative dimensions of adult learning. San Francisco: Jossey-Bass, } \\
1991 \text {. } \\
\text { - Contemporary paradigms of learning. Adult Education Quarterly, v.46, } \\
\text { n.3, p. } 158-173,1996 .\end{array}$ & 07 \\
\hline $\begin{array}{l}\text { Brown, J.; } \\
\text { Duguid, P. }\end{array}$ & $\begin{array}{l}\text { - Organizational learning and communities-of-practice: towards a unified } \\
\text { view of working, learning and innovation. Organization Science, v. 2, n. } \\
\text { 1, p. 40-57, 1991. }\end{array}$ & 07 \\
\hline Elkjaer, B. & $\begin{array}{l}\text { - Em busca de uma teoria de aprendizagem social. In: EASTERBY- } \\
\text { SMITH, M.; BURGOYNE, J.; ARAÚJO, L. Aprendizagem } \\
\text { organizacional e organização de aprendizagem: desenvolvimento na teoria } \\
\text { e na prática. São Paulo: Atlas, 2001.p. 100-116. }\end{array}$ & 04 \\
\hline $\begin{array}{l}\text { Merriam, S.; } \\
\text { Cafarella, R. S. }\end{array}$ & $\begin{array}{l}\text { - Learning in adulthood: a comprehensive guide. California: Jossey Bass } \\
\text { Inc., } 1991 .\end{array}$ & 04 \\
\hline $\begin{array}{l}\text { Sonnentag, S.; } \\
\text { Niessen, C.; } \\
\text { Ohly, S. }\end{array}$ & $\begin{array}{l}\text { - Learning at work: training and development. In C. L. Cooper, \& I. T. } \\
\text { Robertson (Eds.). International Review of Industrial and Organizational } \\
\text { Psychology (Vol. 19, pp. 249-289). London: John Wiley and Sons, } 2004 .\end{array}$ & 04 \\
\hline
\end{tabular}
Fonte: Dados coletados pelos autores (2013).

Da literatura internacional, a maior frequência de citações (21) relaciona-se à abordagem sociológica da aprendizagem de Gherardi e Nicolini, para quem a aprendizagem REAd | Porto Alegre - Edição 80 - N 1 - janeiro/abril 2015 - p. 57-88 
A produção sobre aprendizagem informal nas organizações no Brasil: mapeando o terreno e rastreando possibilidades futuras

não é algo que ocorre só ou principalmente na mente dos indivíduos, mas que deriva da participação destes em atividades sociais. Gherardi e Nicolini também são citados pelos conceitos de learning-in-organizing (conhecimento adquirido por meio da prática como forma de perpetuar tal conhecimento) e reflexividade (processo de traduzir o conhecimento prático em conhecimento explícito).

Os próximos dois autores mais citados, com 15 referências, são Argyris e Schön, cujas menções referem-se à aprendizagem individual e organizacional e, devido à grande influência dos trabalhos de Schön, à investigação sobre a prática reflexiva e aprendizagem na ação. Schön, em sua obra The reflective practitioner (1983), aparece sozinho com 12 menções ao desenvolvimento da teoria e da prática da aprendizagem do profissional reflexivo no século XX. Oriundas da obra Educação e Experiência (1979), de John Dewey (9), está o trabalho de Kolb (15), quem difundiu a ELT - Experiential Learning Theory, ou Teoria da Aprendizagem Experiencial. Para o autor, aprendizagem é um processo e não resultados, que envolve a experiência imediata da relação entre educação, trabalho e desenvolvimento pessoal.

Na sequência, com 12 citações, estão Lave e Wenger, que cunharam a expressão participação periférica legítima para designar o processo por meio do qual o profissional principiante se apropria dos saberes necessários à prática profissional, através da sua participação social. Antonacopoulou, com 10 citações, aborda a aprendizagem como um fenômeno com dimensões reflexivas e emocionais. Em capítulo de livro, Easterby-Smith e Araújo, citados 10 vezes, apresentam as diferenciações entre aprendizagem organizacional e organizações que aprendem e, em artigo, abordam o conceito de comunidades de prática, o que também é feito por Wenger (8), e Brown e Duguid (7).

Os conceitos de aprendizagem informal, incidental, formal e estratégias de aprendizagem no trabalho são inseridos nos estudos por Marsick e Watkins (9) e por Sonnentag, Niessen e Ohly (4). Por sua vez, a aprendizagem de adultos é tratada nas obras de Jack Mezirow (7) e Merriam e Cafarella (4). Destaca-se ainda Elkjaer (4), que propõe a teoria da aprendizagem social a partir de uma discussão em torno dos conceitos de aprendizagem situada, aprendizagem baseada em práticas, teoria da atividade, aprendizagem enquanto processo cultural e comunidades de prática.

Os autores nacionais referenciados estão dispostos no Quadro 6. 
Diogo Reatto \& Arilda Schmidt Godoy

Quadro 6 - Literatura nacional e autores referenciados nos estudos

\begin{tabular}{|c|c|c|}
\hline $\begin{array}{c}\text { Autores } \\
\text { nacionais }\end{array}$ & Obras mais referenciadas & Frequência \\
\hline $\begin{array}{l}\text { Antonello, C. } \\
\text { S. }\end{array}$ & $\begin{array}{l}\text { - A metamorfose da aprendizagem organizacional: uma revisão crítica. RUAS, } \\
\text { R. L.; ANTONELLO, C. S.; BOFF, L. H. (Orgs.) Os novos horizontes da } \\
\text { gestão: aprendizagem organizacional e competências. Porto Alegre: Bookman, } \\
\text { 2005.p. 12-33. } \\
\text { - As formas de aprendizagem utilizadas por gestores no desenvolvimento de } \\
\text { competências. In: ENCONTRO NACIONAL DOS PROGRAMAS DE PÓS- } \\
\text { GRADUAÇÃO EM ADMINISTRAÇÃO - ENANPAD, 28., 2004, Curitiba. } \\
\text { - Aprendizagem na ação revisitada e sua relação com a noção de competência. } \\
\text { Comportamento Organizacional e Gestão, Lisboa, v. 1, p. 17-37, 2006. }\end{array}$ & 22 \\
\hline Abbad, G. & $\begin{array}{l}\text { - Avaliação de treinamento: análise da literatura e agenda de pesquisa. Revista de } \\
\text { Administração da Universidade de São Paulo, v. 38, n. 3, p. 205-218, } 2003 \text {. }\end{array}$ & 06 \\
\hline $\begin{array}{l}\text { Brandão, H. } \\
\text { P.; Borges- } \\
\text { Andrade, J. E. }\end{array}$ & $\begin{array}{l}\text { - Competências no trabalho: uma revisão crítica da produção científica brasileira. } \\
\text { Revista Estudos de Psicologia, v. 12, n. 2, 149-158, } 2007 .\end{array}$ & 05 \\
\hline Freire, $\mathrm{P}$. & $\begin{array}{l}\text { - Pedagogia da autonomia: saberes necessários à prática educativa. São Paulo: } \\
\text { Paz e Terra, } 1996 .\end{array}$ & 05 \\
\hline Ruas, R. & $\begin{array}{l}\text { - Desenvolvimento de competências gerenciais e a contribuição da aprendizagem } \\
\text { organizacional. In: FLEURY, M. T.; OLIVEIRA JUNIOR, M. (Org.). Gestão } \\
\text { estratégica do conhecimento. São Paulo: Atlas, } 2001 .\end{array}$ & 05 \\
\hline $\begin{array}{l}\text { Pantoja, M. J.; } \\
\text { Borges- } \\
\text { Andrade, J. E. }\end{array}$ & $\begin{array}{l}\text { - Contribuições teóricas e metodológicas da abordagem multinível para o estudo } \\
\text { da aprendizagem e sua transferência nas organizações. Revista de } \\
\text { Administração Contemporânea, v. } 8 \text {, n. 4, p. 115-138, 2004. }\end{array}$ & 03 \\
\hline
\end{tabular}
Fonte: Dados coletados pelos autores (2013).

Em relação à literatura nacional usada nos estudos levantados (Quadro 6), foram mencionados 51 diferentes autores, perfazendo um total de 102 citações. Destacam-se os trabalhos de Antonello que focam os processos de aprendizagem gerenciais baseados em práticas (com 22 citações) e o de Abbad cujo principal foco é o suporte e a transferência de aprendizagem na área de treinamento e desenvolvimento (com 6 citações). Vale a pena aqui destacar que Godoy e Antonello (2011), em trabalho de revisão sobre a aprendizagem organizacional no Brasil, mencionam Abbad como a autora mais citada em estudos com a mesma temática.

Ainda são destacados os autores com 5 citações: Brandão e Borges-Andrade com um texto de revisão teórica que relaciona competências e aprendizagem no trabalho; Ruas, em seu capítulo que aborda o desenvolvimento de competências gerenciais; e Paulo Freire com sua obra de pedagogia de corrente progressista e crítica que influenciou, também, os trabalhos de Mezirow (1991). Por fim, Pantoja e Borges-Andrade são citados 3 vezes fazendo-se referência ao artigo teórico dos autores sobre a capacidade que o indivíduo deve ter de transferir novos conhecimentos às suas rotinas de trabalho.

\subsection{Níveis de Aprendizagem Informal}

No tocante ao nível de análise empregado nos estudos examinados, o Quadro 7 mostra REAd | Porto Alegre - Edição 80 - N 1 - janeiro/abril 2015 - p. 57-88 
A produção sobre aprendizagem informal nas organizações no Brasil: mapeando o terreno e rastreando possibilidades futuras

que foi focado, predominantemente, o nível individual (12). A AI no nível do grupo foi abordada em 3 artigos e, no nível organizacional, em 2 deles. Apenas 1 artigo abordou dois níveis de aprendizagem concomitantes - individual e organizacional. Já o nível interorganizacional foi declarado em apenas um artigo. Os outros três trabalhos classificados como "não foi possível identificar" tratam-se de ensaios teóricos.

Quadro 7 - Nível de estudos investigados

\begin{tabular}{|l|c|}
\hline \multicolumn{1}{|c|}{ Nível de análise } & Total \\
\hline Individual & 12 \\
\hline Grupal & 3 \\
\hline Organizacional & 2 \\
\hline Interorganizacional & 1 \\
\hline Não foi possível identificar & 3 \\
\hline \multicolumn{2}{|c|}{ Fonte: Dados coletados pelos autores (2013). }
\end{tabular}

Esses resultados mostram que o processo de AI nos artigos examinados tem sido tratado a partir de suas características individuais, pois cada pessoa tem suas próprias necessidades, motivações, oportunidades e iniciativas que a leva a aprender (MARSICK; WATKINS, 2001; CUNNINGHAM; HILLIER, 2013). Esse processo de aprendizagem é único em cada pessoa e depende de como o indivíduo constrói seu conhecimento em diferentes situações no trabalho (LE CLUS, 2011). A interação social com os demais colegas também tem sua significância no processo de aprendizagem (ERAUT, 2004), contudo, o controle "do que" e "como" se aprende está nas mãos de cada indivíduo (MARSICK; WATKINS, 2001). Mesmo naqueles estudos que focaram outros níveis, observou-se que o foco de atenção sempre foi o indivíduo como representante da organização.

Nos estudos analisados, pode-se observar que foi conferida especial atenção ao nível microorganizacional e às interações dos indivíduos nos pequenos grupos, o que pode sugerir que os pesquisadores consideraram o fato de que a AI invoca sempre o indivíduo e, depois, as suas interações nos níveis nos quais está inserido: grupo, intergrupo, organizacional e interorganizacional (ANTONELLO; GODOY, 2011). Os estudos remetem, portanto, à habilidade de o indivíduo aprender com base em suas experiências, de aprender dos e com outros em seus ambientes de trabalho (EASTERBY-SMITH; BURGOYNE; ARAUJO, 2001).

\subsection{Análise das perspectivas teóricas de Aprendizagem Informal}

Embora Godoy e Antonello (2011) tenham desenvolvido seu estudo focando o campo da aprendizagem organizacional, considerou-se que, dada a proximidade das temáticas, as categorias usadas pelas autoras seriam úteis e pertinentes também ao exame da perspectiva 
teórica envolvida nos estudos acerca da AI. O Quadro 8 sintetiza os resultados encontrados. Não foi possível classificar 6 trabalhos por se tratar de ensaios teóricos ou revisões de literatura, embora um artigo de revisão de literatura sobre o contexto social da aprendizagem de gerentes tenha declarado em seu resumo a opção pela perspectiva psicológica social. Também não se encontraram estudos de AI alinhados às perspectivas antropológica, política, econômica e histórica.

Quadro 8 - Perspectivas teóricas adotadas nos estudos

\begin{tabular}{|c|c|c|c|}
\hline Perspectivas teóricas de aprendizagem & $\begin{array}{c}\text { Adoção de uma } \\
\text { perspectiva }\end{array}$ & $\begin{array}{l}\text { Adoção de duas ou } \\
\text { mais perspectivas }\end{array}$ & Total \\
\hline \multirow{3}{*}{ Psicológica } & 1 & 0 & 1 \\
\hline & 4 & 2 & 6 \\
\hline & 3 & 1 & 4 \\
\hline Sociológica & 1 & 0 & 1 \\
\hline Ciência da Administração & 5 & 1 & 6 \\
\hline Não foi possível identificar & 6 & 0 & 6 \\
\hline
\end{tabular}

Fonte: Dados coletados pelos autores (2013).

Verificou-se que as perspectivas teóricas comumente adotadas nos estudos são a Psicológica e a Ciência da Administração. Sob a perspectiva Psicológica estão os trabalhos que acreditam que o processo de aprendizagem é individual porque acontece unicamente na mente do indivíduo. Nessa perspectiva, há os estudos que tratam a aprendizagem informal como socialmente construída nas relações e interações entre as pessoas - psicológica social e os que adotam a noção de aprendizagem pela experiência e na ação - psicológica aplicada. Observa-se que mesmo os autores Gherardi e Nicolini liderando o número de citações nos trabalhos, a aprendizagem ainda é vista por um prisma psicológico e não como algo fundamentalmente produzido e reproduzido nas relações sociais. Na perspectiva relacionada à Ciência da Administração destacam-se os trabalhos inspirados nas bases teóricas da aprendizagem organizacional de Argyris, Schön e da aprendizagem experiencial de Kolb, que destacam que a aprendizagem acontece a partir da experiência dos aprendizes sendo refletida enquanto ocorre a ação.

\subsection{Paradigmas de pesquisa}

O esforço em identificar os paradigmas - declarados ou não - que orientaram as pesquisas que tratam do tema AI está apoiado na ideia de que é importante os pesquisadores utilizarem metodologias consistentes com suas suposições filosóficas, ontológicas (de como ele entende o que é conhecimento), epistemológicas (como ele o identifica) e axiológicas (que valores o compõem) (CRESWELL, 2007; GEPHART, 1999). Assim como no trabalho de Godoy e Antonello (2011), optou-se por Gephart (1999) e Guba e Lincoln (1994) para a 
A produção sobre aprendizagem informal nas organizações no Brasil: mapeando o terreno e rastreando possibilidades futuras

tipologia de paradigmas adotada: positivismo e pós-positivismo, interpretacionismo e construcionismo e pós-modernismo crítico.

Para a análise dos paradigmas de pesquisa (Quadro 9), consideraram-se apenas os artigos que envolviam pesquisas empíricas - qualitativas, quantitativas e mistas (14). Desses 14 trabalhos, 8 declararam sua opção pelo paradigma interpretacionista, todos utilizando metodologias qualitativas. Os demais seis trabalhos não se declararam positivista ou póspositivista, contudo foram assim classificados porque se valeram de metodologias quantitativas cujos objetivos eram testar modelos ou escalas de aprendizagem, classificar e comparar estratégias de aprendizagem e estabelecer relações entre variáveis. Um dos trabalhos que envolveu pesquisa de métodos mistos foi considerado pós-positivista, pois a etapa qualitativa foi exploratória visando à construção do instrumento de coleta de dados utilizado na etapa quantitativa.

Quadro 9 - Paradigmas de pesquisa

\begin{tabular}{|c|c|c|c|c|}
\hline \multicolumn{4}{|c|}{ Paradigmas de pesquisa } & \multirow{2}{*}{ Total } \\
\hline Positivismo & $\begin{array}{c}\text { Pós- } \\
\text { positivismo }\end{array}$ & Interpretacionismo & $\begin{array}{c}\text { Pós- } \\
\text { modernismo/crítico }\end{array}$ & \\
\hline \multicolumn{2}{|c|}{6} & & & 6 \\
\hline & & 8 & 0 & 8 \\
\hline & & & 0 \\
\hline
\end{tabular}

Fonte: Dados coletados pelos autores (2013).

Para a classificação dos paradigmas, consideraram-se a explicitação dos procedimentos metodológicos, a forma de tratamento e apresentação dos resultados, o tipo de conhecimento que se pretendia alcançar e os achados efetivamente expressos de acordo com os objetivos da pesquisa.

\subsection{Tipos de pesquisa}

Dos 21 documentos analisados, doze declararam o tipo de pesquisa adotado. Os restantes foram classificados a partir da leitura dos procedimentos metodológicos e/ou da forma como os autores apresentaram os dados ou informações levantadas e discutiram os resultados (Quadro 10). 
Diogo Reatto \& Arilda Schmidt Godoy

Quadro 10 - Tipos de pesquisa

\begin{tabular}{|ll|c|}
\hline \multicolumn{2}{|c|}{ Tipos de pesquisa } & Total \\
\hline Revisão de literatura & & 3 \\
\hline Ensaio teórico & & 4 \\
\hline \multirow{2}{*}{ Pesquisa quantitativa } & $\begin{array}{l}\text { Survey } \\
\text { Correlacional }\end{array}$ & 2 \\
\hline & Análise do discurso & 1 \\
\cline { 2 - 3 } & Estudo de caso & 1 \\
\cline { 2 - 3 } Pesquisa qualitativa & Estudo qualitativo básico ou genérico & 3 \\
\cline { 2 - 3 } & Fenomenologia & 2 \\
\cline { 2 - 3 } & História de vida & 1 \\
\cline { 2 - 3 } & Narrativa & 2 \\
\hline Pesquisa mista & Survey + entrevistas & 1 \\
\hline
\end{tabular}

Fonte: Dados coletados pelos autores (2013).

Assim como Godoy e Antonello (2011) encontraram em seu estudo sobre aprendizagem organizacional, a metodologia qualitativa é a predominante no estudo da AI, principalmente os estudos qualitativos básicos ou genéricos (MERRIAM, 1998). Dos nove trabalhos qualitativos, oito declararam o tipo de pesquisa. $\mathrm{O}$ único que não declarava trazia o tipo de pesquisa no título ao empregar Histórias de Vida para estudar Aprendizagem Informal de gerentes. A leitura dos artigos também permite afirmar haver coerência entre os tipos de pesquisa qualitativa declarados e o paradigma interpretacionista (declarado ou inferido).

Três pesquisas qualitativas foram classificadas como estudos qualitativos básicos ou genéricos. Essa denominação é adotada por Merriam (2002, p. 6) para referir-se aos estudos que têm como objetivo "descobrir e compreender um fenômeno, um processo, ou as perspectivas e visão de mundo das pessoas nele envolvidas" contendo as características essenciais da metodologia qualitativa sem, no entanto, apresentar todos os requisitos que possibilitariam o seu enquadramento como um estudo de caso, estudo etnográfico, etnometodologia, grounded theory, ou qualquer outra modalidade específica. Dentre as modalidades específicas de pesquisa qualitativa foram encontrados dois trabalhos de caráter fenomenológico, um estudo de caso, uma história de vida, uma pesquisa com foco na análise do discurso e uma com foco na análise de narrativas. Não foram encontradas pesquisas etnográficas, pesquisa-ação e pesquisa documental que também estavam presentes no estudo de Godoy e Antonello (2011).

É importante ainda destacar que sete trabalhos - o que corresponde a um terço da produção analisada - não envolveram pesquisa de campo trazendo discussões de natureza teórica e de revisão da literatura.

\subsection{Natureza do estudo}

Para classificar os artigos encontrados de acordo com sua natureza, usaram-se as REAd | Porto Alegre - Edição 80 - N 1 - janeiro/abril 2015 - p. 57-88 
A produção sobre aprendizagem informal nas organizações no Brasil: mapeando o terreno e rastreando possibilidades futuras

quatro categorias propostas por Godoy e Antonello (2011), como mostra o Quadro 11. Dos vinte e um trabalhos que tratavam a $\mathrm{AI}$, onze declararam sua questão de pesquisa, o que ajudou na classificação dos trabalhos. A natureza do estudo dos demais artigos foi inferida por meio de leitura integral do trabalho, observando-se a questão de pesquisa e a sua relação com o tipo de pesquisa, com os objetivos e com os métodos usados para atingi-los.

Como as categorias acerca da natureza do estudo não são excludentes, o total apresentado no quadro abaixo não corresponde ao total dos artigos. Assim, vale a pena destacar que um dos estudos que se valeu do método misto tinha como objetivo classificar e, posteriormente, descrever os resultados. A predominância de trabalhos cuja natureza é descrever e narrar ilustra a tendência do tema da AI ser investigado usando metodologias predominantemente qualitativas.

Quadro 11 - Natureza do estudo

\begin{tabular}{|c|c|}
\hline Natureza do estudo & Total \\
\hline $\begin{array}{l}\text { Disseminação/divulgação/elaboração teórica } \\
\text { Estudos que têm como objetivo fundamental disseminar, divulgar e organizar o conhecimento } \\
\text { existente (como nas revisões de literatura), assim como aqueles que usam o conhecimento existente } \\
\text { para elaborar um trabalho profundo e criativo de reflexão sobre um corpo teórico, envolvendo alto } \\
\text { nível de organização, de interpretação e de julgamento pessoal (como esperado nos ensaios teóricos) }\end{array}$ & 6 \\
\hline $\begin{array}{l}\text { Descrever/narrar } \\
\text { Estudos que descrevem, a partir de dados e/ou informações coletados na realidade, as características } \\
\text { de uma determinada população ou fenômeno humano e social. Englobam estudos cujo interesse } \\
\text { fundamental é identificar as características, opiniões, percepções, atitudes e/ou crenças de um } \\
\text { determinado grupo (indivíduos e/ou empresas). Geralmente são organizados adotando o formato de } \\
\text { uma survey ou de uma pesquisa qualitativa. }\end{array}$ & 10 \\
\hline \multirow{4}{*}{$\begin{array}{ll}\text { Testar/verificar } & \text { Teorias/modelos } \\
\text { Estudos que testam ou verificam teorias, modelos, hipóteses, } & \text { Hipóteses } \\
\text { pressupostos e conceitos/construtos. Estudos desta natureza podem ser } & \text { Conceitos/construtos } \\
\text { encontrados nas pesquisas quantitativas organizadas em formatos que } & \\
\text { envolvem teste de hipóteses, de construtos (por exemplo, nos estudos que } & \\
\text { validam escalas de medida) e de modelos (como, por exemplo, a } & \text { Premissas/pressupostos } \\
\text { modelagem de equações estruturais) e nos estudos de caso. } & \end{array}$} & 1 \\
\hline & 2 \\
\hline & 0 \\
\hline & 2 \\
\hline \multirow{2}{*}{$\begin{array}{l}\text { Desenvolver/gerar } \\
\text { Estudos cujo objetivo fundamental é desenvolver ou gerar teorias, } \\
\text { modelos, hipóteses e conceitos/construtos. }\end{array}$} & 1 \\
\hline & 0 \\
\hline
\end{tabular}

Fonte: Dados coletados pelos autores (2013).

\subsection{Amostra e/ou sujeitos pesquisados}

Para esta análise, consideraram-se somente os trabalhos com pesquisa empírica (14). A maior parte dos estudos explicitou de forma clara o universo, a população, a descrição da amostra e dos sujeitos de pesquisa.

Quanto à pessoa/função/categoria, ainda há sutil preferência pelos sujeitos que ocupam função gerencial em organizações (7), sejam públicas, privadas ou do terceiro setor. Os demais trabalhos foram realizados com funcionários que não ocupam função de representação organizacional (5), como funcionários de diversas áreas dentro de organizações REAd | Porto Alegre - Edição 80 - No 1 - janeiro/abril 2015 - p. 57-88 
como tecnologia, industrial, administrativo, educação, atendimento e alimentação. Dois trabalhos tiveram como foco de estudo a organização, porém um deles - desenvolvido a partir de história de vida - focou um indivíduo como representante daquela organização.

Quadro 12-Segmento de atuação da amostra e/ou sujeitos pesquisados

\begin{tabular}{|l|l|c|}
\hline \multicolumn{2}{|c|}{ Segmento de atuação dos sujeitos } & Total \\
\hline Setor público & Serviços & 4 \\
\hline Setor privado & Industrial & 1 \\
\hline \multicolumn{2}{|l|}{ Serviços } & 6 \\
\hline ONGs & Agropecuário & 0 \\
\hline Cooperativa de Agronegócio & 1 \\
\hline Multisegmentário & 1 \\
\hline
\end{tabular}

Fonte: Dados coletados pelos autores (2013).

Como mostra o Quadro 12, os estudos de AI ainda estão focados no segmento privado, o que também foi registrado por Godoy e Antonello (2011) em seu trabalho sobre aprendizagem organizacional.

\subsection{Principais achados/resultados}

Esta seção sistematiza os achados/resultados dos estudos analisados verificando se esses achados/resultados são coerentes, ou não, com os objetivos explicitados.

Os estudos que buscam compreender que sentido os indivíduos dão ao seu trabalho, em que medida as organizações apoiam a aprendizagem que ocorre no seu interior e as consequentes formas pelas quais aprendem estão focados, principalmente, em identificar quais são os processos de $\mathrm{AI}$. Os resultados identificam a predominância dos processos informais de aprendizagem no cotidiano laboral, o que gera uma lista extensa de atividades e dinâmicas que ocorrem informalmente no dia-a-dia, no contato com colegas e chefes, pela observação, improvisação, em conversas com pessoas julgadas mais sábias ou experientes, com a prática, com a experiência, com a interação e a reflexão presentes no processo de aprender. Também afirmam que os processos de AI são diferentes de acordo com as funções que o indivíduo desempenha no grupo, dependem dos contextos nos quais as organizações estão inseridas e, principalmente, pelo sentido que o indivíduo dá ao seu trabalho, pois a compreensão do significado que cada um tem do trabalho é o sustentáculo para os processos de aprendizagem.

Mesmo os trabalhos que apontaram que a aprendizagem inicial de um indivíduo no trabalho é vista como um produto resultante de uma atividade formalmente estruturada, como cursos preparatórios e treinamentos, afirmam que a continuidade da aprendizagem, após esta experiência formal, se dá como um processo informal no convívio com os demais do mesmo 
A produção sobre aprendizagem informal nas organizações no Brasil: mapeando o terreno e rastreando possibilidades futuras

grupo, na vivência de práticas profissionais coletivas, no pertencimento a comunidades de prática, no enfrentamento de situações inéditas e no refletir sobre as práticas individuais e coletivas, mostrando, assim, que a aprendizagem não é um processo linear, mas multifacetado.

Os achados/resultados dos estudos cuja preocupação é identificar e descrever os processos de aprendizagem sob uma ou mais abordagens da AI, de acordo com os diversos sinônimos apresentados por Marsick e Watkins (2001), destacam a aprendizagem baseada na prática e o seu contexto, sustentada, principalmente, na literatura sobre aprendizagem situada, a qual não acontece somente em comunidades de prática. Características como a participação periférica legitimada devem ser fomentadas para que a cultura da aprendizagem se propague. No nível organizacional, o conhecimento obtido pela experiência de uma empresa em mercados externos pode oferecer vantagens que refletem no desempenho de suas subsidiárias e um contexto para interpretar mercados, para aumentar o conhecimento sobre clientes, fornecedores, concorrência, governos, normas e valores institucionais, permitindo novas oportunidades de negócio e reduzindo a incerteza.

Os estudos que investigam o processo de AI de indivíduos que desenvolvem funções gerenciais, visando a identificar como os gerentes aprendem, ressaltaram, além dos processos de aprendizagem já mencionados anteriormente nesta seção, as experiências vividas fora do contexto profissional e os valores aprendidos em família e na escola como influenciadores do conteúdo e do processo de aprendizagem gerencial. Consideram, ainda, de extrema relevância a busca de elementos do passado histórico do indivíduo para compreender os processos que se desenrolam no presente. Por sua vez, os achados dos estudos dos processos de AI nos indivíduos que não ocupam função gerencial remeteram ao conceito de aprendizagem situada e aos conceitos de participação, identidade, prática e a dinâmica entre eles. O processo de AI que mais se destacou foi o de ajuda interpessoal.

Os achados dos estudos que se preocuparam em perceber como o contexto social influencia os processos de aprendizagem do indivíduo e quais são esses processos apontam para a forte influência de um contexto de participação social nas práticas cotidianas no trabalho, como esse ambiente contribui com o desenvolvimento das competências do indivíduo e que a aprendizagem não é um fenômeno individual, mas coletivo e que ocorre a partir das interações sociais.

Um dos artigos da categoria de estudos que descrevem, analisam e discutem novas formas de se abordar e pesquisar a AI identificou a história de vida como estratégia REAd | Porto Alegre - Edição 80 - No 1 - janeiro/abril 2015 - p. 57-88 
Diogo Reatto \& Arilda Schmidt Godoy

metodológica qualitativa capaz de captar as diversas dimensões e influências envolvidas simultaneamente na aprendizagem dos indivíduos, contribuindo no resgate da valorização humana e trazendo entendimentos de fenômenos coletivos a partir de relatos de vivências e experiências pessoais. Os demais artigos advertem que os saberes produzidos na academia são divulgados como superiores aos saberes práticos e que o conhecimento adquirido na prática é visto de forma pejorativa; porém, a aprendizagem na prática, a aprendizagem como prática e a visão alternativa que enfatiza o ensaiar são aspectos chave da aprendizagem.

Por fim, embora só tenha havido um estudo que abordasse a função e o impacto dos sentimentos dos indivíduos na AI, os resultados indicaram que erro profissional, revés na carreira e trauma pessoal são os sofrimentos emocionais que mais afetam a aprendizagem dos funcionários. Outro trabalho apontou o sofrimento como um processo de aprendizagem na carreira gerencial.

Conclui-se que os achados/resultados dos estudos levantados responderam aos objetivos propostos pelos autores dos trabalhos o que facilitou o agrupamento das conclusões apresentadas pelos pesquisadores. No entanto, verificou-se a discussão de muitos achados/resultados que não foram pensados a priori, porém que não foram descartados.

\subsection{Dados de contexto: pesquisadores e grupos de pesquisa}

Fez-se a análise dos dados dos pesquisadores preocupando-se em obter os resultados esquematizados por região, estado, universidade e programas de pós-graduação aos quais poderiam estar vinculados (Quadro 13).

REAd | Porto Alegre - Edição 80 - No 1 - janeiro/abril 2015 - p. 57-88 
A produção sobre aprendizagem informal nas organizações no Brasil: mapeando o terreno e rastreando possibilidades futuras

Quadro 13 - Dados de contexto

\begin{tabular}{|c|c|c|c|c|}
\hline Região & Estado & Programa/Instituição & & \\
\hline \multirow{6}{*}{ Sul } & \multirow{5}{*}{$\begin{array}{l}\text { Rio Grande do } \\
\text { Sul }\end{array}$} & PPGA da UFRGS & 8 & \multirow{6}{*}{20} \\
\hline & & PPG-Agronegócios/CEPAN/UFRGS & 1 & \\
\hline & & $\begin{array}{l}\text { Grupo de Estudos e Pesquisas em Estratégia e } \\
\text { Inovação da PUC-RS }\end{array}$ & 1 & \\
\hline & & $\begin{array}{l}\text { Faculdade de Administração do Grupo Educacional } \\
\text { Unificado }\end{array}$ & 1 & \\
\hline & & UFSM & 6 & \\
\hline & Santa Catarina & UFSC & 3 & \\
\hline \multirow{10}{*}{ Sudeste } & \multirow{6}{*}{ Minas Gerais } & UFMG & 1 & \multirow{10}{*}{14} \\
\hline & & CEPEAD/UFMG & 2 & \\
\hline & & UFU & 1 & \\
\hline & & FUNCESI & 1 & \\
\hline & & PPGA da UFLA & 3 & \\
\hline & & UFVJM & 1 & \\
\hline & Rio de Janeiro & UFRRJ & 1 & \\
\hline & \multirow{3}{*}{ São Paulo } & PPGA da UPM & 1 & \\
\hline & & FGV/SP & 2 & \\
\hline & & FEA/USP & 1 & \\
\hline \multirow{5}{*}{ Nordeste } & Paraíba & PPGA da UFPB & 3 & \multirow{5}{*}{8} \\
\hline & & UFPE & 2 & \\
\hline & Pernambuco & FACIPE & 1 & \\
\hline & Ceará & UNIFOR & 1 & \\
\hline & $\begin{array}{l}\text { Rio Grande do } \\
\text { Norte }\end{array}$ & Universidade Potiguar & 1 & \\
\hline \multirow{4}{*}{$\begin{array}{l}\text { Centro- } \\
\text { Oeste }\end{array}$} & \multirow{4}{*}{ Distrito Federal } & PPGA da UnB & 2 & \multirow{4}{*}{07} \\
\hline & & $\begin{array}{l}\text { PPG em Psicologia da Universidade Salgado de } \\
\text { Oliveira }\end{array}$ & 1 & \\
\hline & & PPG em Psicologia da UnB & 1 & \\
\hline & & Instituto de Psicologia/UnB & 3 & \\
\hline Norte & Amazonas & UFAM/FES/DA & 1 & 1 \\
\hline
\end{tabular}

Assim, identificou-se que os pesquisadores que investigam AI no Brasil concentramse, predominantemente, no estado do Rio Grande do Sul e de Minas Gerais, seguido pelo Distrito Federal e pelo estado de São Paulo. Contudo, ao analisar essa produção baseada nos temas de estudo e abordagem paradigmática, notaram-se dois grupos com temáticas alinhadas: PPGA da UFRGS e PPG em Psicologia da UnB juntamente com demais pesquisadores do seu Instituto de Psicologia.

No primeiro grupo destacam-se as pesquisas interacionistas centradas nos processos de aprendizagem gerenciais e não gerenciais no trabalho. $\mathrm{O}$ segundo grupo concentra seus estudos numa abordagem pós-positivista com pesquisas quantitativas ou multimétodos cujos temas são o suporte e o apoio à aprendizagem e as estratégias cognitivas de aprendizagem.

Embora, quantitativamente, autores do estado de Minas Gerais sejam relevantes, seus estudos não indicam a constituição de um núcleo já estabelecido de estudos na área de AI. São estudos isolados com temáticas que variam dos saberes administrativos e gerenciais aos REAd | Porto Alegre - Edição 80 - № 1 - janeiro/abril 2015 - p. 57-88 
processos de aprendizagem informais, na prática, no local de trabalho e aprendizagem de adultos. A mesma tendência é observada nos estudos dos autores de instituições do estado de São Paulo, somando-se às temáticas já mencionadas os estudos de AI e desenvolvimento de competências e de áreas relacionadas à educação.

Dessa forma, não há evidências de formação de redes de pesquisadores que estejam focando o tema no Brasil, apenas um conjunto de publicações isoladas associadas a determinados programas de pós-graduação e seus egressos.

\section{CONSIDERAÇÕES FINAIS}

Esta revisão de literatura objetivou identificar, descrever e analisar a produção no campo de estudos de Aprendizagem Informal nas organizações no Brasil entre 2006 e 2012. Ressalta-se que não foram contemplados trabalhos apresentados em congressos e publicados em seus anais, considerando-se somente a publicação definitiva em periódicos indexados.

Quando se retoma o posicionamento ontológico e epistemológico sobre a AI, a gênese de seus estudos está na Educação, em especial na educação de adultos. No entanto, o discurso sobre essas áreas foi mal interpretado a partir do momento em que passou a significar estritamente educação vocacional, ou educação voltada para o trabalho, valorizando-se o saber-fazer e se esquecendo da influência que o discurso de outras áreas como a sociologia, a psicologia cognitiva e a antropologia podem ter sobre a AI (GARRICK, 1998). Por isso, a discussão sobre o tema ganha diversos matizes de acordo com a formação acadêmica e os interesses de quem sobre ela discorre e conforme o uso que se quer fazer dela. Assim, cada autor deve posicionar-se discursivamente em seus estudos acerca do que a AI pode abranger e o que ela deve excluir, desde abordagens que levem à emancipação do indivíduo rumo a um aprendizado autodirigido, fruto do seu viver, da sua experiência nas atividades cotidianas (Aprendizado Vivencial/Experiencial) e das suas relações sociais (GARRICK, 1998; HAGER, 2012), até abordagens formadas no cerne corporativo, como a da aprendizagem no local de trabalho e a de organizações que aprendem (GARRICK, 1998).

Ainda sobre a conceituação de AI, Malcolm, Hodkinson e Colley (2003) alertam para a falta de concordância na literatura sobre o que é AI e quais os limites entre ela e a aprendizagem formal. Da leitura dos artigos analisados nesta revisão, pode-se inferir que os estudos nacionais não se preocupam em delimitar com maior clareza o que está contemplado no âmbito da conceituação de AI, adotando definições genéricas e cotidianas sobre o tema. Com isso, esses autores acabam desprezando a natureza contextual da AI. Uma possível 
A produção sobre aprendizagem informal nas organizações no Brasil: mapeando o terreno e rastreando possibilidades futuras

explicação para a ausência de uma conceituação mais precisa sobre o termo nos estudos nacionais é o fato de que, na literatura internacional, os autores que estudam o tema AI geralmente são da área de educação de adultos, na qual está a origem do conceito, enquanto que os autores nacionais da área de Administração ainda se apoiam numa literatura americana relacionada à área de treinamento e desenvolvimento de recursos humanos e não identificaram a relevância de outras referências que lhes possibilitem refletir sobre a AI como uma forma válida de aquisição de conhecimento. Malcolm, Hodkinson e Colley (2003) também sugerem que se evite a afirmação de que AI pode ser entendida como superior à aprendizagem formal (ou o contrário), reconhecendo-se elementos de formalidade e informalidade em qualquer processo de aprendizagem, o que sugere que ambas estão interrelacionadas. Antonello (2011) esclarece que adotar esse posicionamento diante da dificuldade de conceituação da AI amplia as possibilidades de leitura e compreensão desse complexo fenômeno.

Essa dificuldade de se conceituar AI reflete nas investigações que focam o tema. Para Eraut (2004), a AI é invisível, porque é vista como óbvia ou não é reconhecida como aprendizagem devido à falta de consciência do indivíduo sobre seus processos de aprender e os resultados deles decorrentes. O autor considera ainda que seu discurso é repleto de códigos, uma vez que é difícil para um indivíduo descrever a natureza do seu próprio trabalho. No intento de atenuar as dificuldades e fazer evoluir as pesquisas na área de AI, são recorrentes as sugestões dos autores nacionais para que se elaborem instrumentos de pesquisa voltados à operacionalização e investigação de ações de AI no trabalho, e que esses instrumentos sejam capazes de captar, mensurar, avaliar e descrever os processos de AI em populações e amostras diferentes, com outras ocupações e níveis hierárquicos e com novas variáveis tais como grau de complexidade da tarefa, valores, crenças e cultura.

Em relação aos focos de investigação da AI, notou-se diversificação. Estudo anterior de Godoy e Antonello (2011) apontou a predileção de trabalhos em pesquisar as oportunidades, facilitadores e obstáculos para a Aprendizagem Organizacional. Este trabalho identificou apenas um artigo com esse objetivo no tocante à AI, o que sugere que os estudos têm substituído a literatura de facilitadores e barreiras da aprendizagem por uma literatura que se preocupa com a maneira pela qual as pessoas atribuem significado a suas experiências de trabalho e reconhecem que os dados sobre AI não têm significados por si mesmos até que as pessoas determinem o que eles representam para o seu trabalho (EASTERBY-SMITH; BURGOYNE; ARAUJO, 2001). Porque, como afirmado por Elkjaer (2001), aprendizagem é 
mais do que processamento de informações, é parte de uma prática social que envolve interpretação. Assim, os focos de investigação dos estudos analisados tendem a estar mais centrados em: (a) compreender o sentido que os indivíduos dão ao seu trabalho; (b) em que medida as organizações apoiam a aprendizagem organizacional; (c) as consequentes formas pelas quais seus funcionários aprendem. A partir dessa mudança de posicionamento teórico, percebe-se uma tentativa de se preocupar em ver a AI como processo e não como produto/resultado de outra atividade (ERAUT, 2011).

Embora a base teórica identificada nos estudos nacionais dê suporte aos focos de pesquisa, a literatura internacional e os autores referenciados nos estudos não são variados. Nota-se, inclusive, que os estudos nacionais não utilizam autores como Eraut, Livingstone, Conlon, Garrick, Gerber e Le Clus entre outros envolvidos com a área de Workplace Learning. Além disso, é importante pontuar que, embora Gherardi e Nicolini tenham liderado o número de citações nos trabalhos, as suas ideias não foram aprofundadas e exploradas no interior dos textos. O que parece estar ocorrendo é uma tentativa de se começar a olhar o fenômeno a partir da perspectiva sociológica da aprendizagem, contudo com uma dificuldade de se abandonar por completo a perspectiva psicológica.

Os principais achados/resultados dos trabalhos levantados, principalmente os de revisão de literatura e ensaios teóricos, remetem à discussão sobre AI atrelando-a à abordagem sociológica ao enfatizar que o ambiente, seja ele familiar ou de trabalho, é fundamental no processo de aprendizagem e que este não é um fenômeno individual, mas construído nas relações e interações sociais. Ouvir o colega de trabalho, conhecer sua história, estreitar os laços de convívio e de relacionamento com colegas e clientes, discutir problemas e soluções na tomada de decisão ou na formulação de estratégias, ensaiar, improvisar e inovar vão muito mais além de simples ações ou atividades no ambiente de trabalho, envolvendo linguagem e artefatos culturais e materiais específicos que podem influenciar na AI. Neste sentido, alguns estudos brasileiros estão chamando atenção para o fato de que a AI nunca é neutra ou independente da socialização dos indivíduos, pois o aprendizado é influenciado pela posição do indivíduo no trabalho ou por qualquer outro ambiente do qual faça parte. Concordam, portanto, com a postura de Garrick (1998) de que o posicionamento social define o acesso ao conhecimento e às experiências de aprendizagem as quais, por sua vez, darão forma à identidade do indivíduo, às suas experiências de vida e à sua noção de realidade.

Outro aspecto importante é a agenda de pesquisa que os autores nacionais propõem, a qual, de acordo com Conlon (2004), deveria se pautar em estudos futuros que busquem 
A produção sobre aprendizagem informal nas organizações no Brasil: mapeando o terreno e rastreando possibilidades futuras

alcançar uma definição comum do que é AI e claro posicionamento de a serviço de que e de quem ela está. Ao examinar as sugestões apontadas pelos autores nacionais, é possível observar que elas se aproximam da preocupação de Conlon (2004) e Eraut (2004; 2011).

Os autores nacionais dos estudos analisados sugerem que se investiguem temas basilares como: (a) porque os processos informais de aprendizagem não são valorizados pela área de Recursos Humanos das organizações; (b) se os investimentos de tempo e dinheiro em processos formais de aprendizagem são suficientes para os profissionais aprenderem; (c) inclusão nas políticas e ações de Recursos Humanos; (d) estímulos e valorização dos processos informais de aprendizagem; (e) aprofundamento do estudo do sentido do trabalho nos processos de aprendizagem. Os ensaios teóricos nacionais sugerem que se façam comparações entre os pensamentos de filósofos como Foucault, novas metáforas e teorias oriundas de outras áreas para a melhor compreensão e ampliação do campo da AI.

O estudo da AI também deve preocupar-se com as mudanças socioeconômicas e ambientais de abrangência global (CONLON, 2004). Para isso, os pesquisadores nacionais indicam estudos futuros que tragam compreensão dos processos de aprendizagem nas organizações e como eles interferem ou se relacionam com a literatura de mudança organizacional. Também, os autores nacionais preocupam-se com a interrelação entre AI e emoções, sofrimentos, prazeres, valores e crenças do indivíduo, questões já reconhecidas como vitais para os indivíduos e organizações, porém negligenciadas por empresas e estudos administrativos (ANTONACOPOULOU; GABRIEL, 2001).

$\mathrm{Na}$ continuidade de sugestões para explorar novo terrenos, os autores nacionais sugerem que uma forma de se conseguir a superação do desafio de se incluir tais temas na discussão sobre AI é olhar para os microprocessos que estão por detrás das práticas contínuas dos atores em um sistema social, aproximando-se dos estudos sociológicos e qualitativos, tais como os estudos de caso e os etnográficos, devido à natureza interpretativa dos processos em questão. Enquanto Conlon (2004) recomenda que tanto os estudos quantitativos quanto os qualitativos devem ser usados para responder às questões de um ambiente de trabalho do século XXI, observa-se a preferência dos autores brasileiros pelas metodologias qualitativas e propõem que os trabalhos quantitativos sejam complementados com pesquisa qualitativa e que os qualitativos complementem seus estudos por meio de outras estratégias qualitativas, como o uso de elementos etnográficos, capazes de captar novas dimensões, influências e entendimentos de vivências e experiências pessoais dos indivíduos, contribuindo para um maior debate e compreensão da AI. No entanto, Eraut (2004) adverte para a dificuldade de se 
conseguir financiamentos para trabalhos etnográficos na maioria dos países, mesmo sabendo que eles podem prover valiosas compreensões sobre aspectos socioculturais da aprendizagem.

Considerando todos esses aspectos, é possível dizer que o estudo da Aprendizagem Informal no Brasil é ainda incipiente e merece um olhar mais cuidadoso da academia, das organizações e dos profissionais das mais diversas áreas e ocupações que buscam um maior entendimento da natureza do seu trabalho e dos processos de aprendizagem - formais e informais - necessários ao seu desenvolvimento. Além de todas as sugestões aqui apresentadas e discutidas, tanto do ponto de vista teórico quanto dos encaminhamentos da pesquisa empírica, é importante também estar atento para que a criação de espaços de promoção da AI nas organizações e nos currículos escolares sejam encorajados, visando a uma compreensão profunda e ampla da natureza complexa, social e reflexiva da Aprendizagem Informal.

\section{REFERÊNCIAS}

ANTONACOPOULOU, E. P. Learning, Working and Living: An Introduction. In: ANTONACOPOULOU, E. et al. Learning, working and living. Mapping the terrain of working life learning. New York. Palgrave Macmillan, p. 2-11, 2006.

E. P.; GABRIEL, Y. Emotion, learning and organizational change. Journal of

Organizational Change Management, v.14, n.5, p. 435-451, 2001.

ANTONELLO, C. S. Saberes no singular? Em discussão a falsa fronteira entre Aprendizagem Formal e Informal. In: ANTONELLO, C. S.; GODOY, A. S. (org.) Aprendizagem organizacional no Brasil. Porto Alegre: Bookman, 2011. p.225-245.

ANTONELLO, C. S.; GODOY, A. S. Uma agenda brasileira para os estudos em Aprendizagem Organizacional. RAE - Revista de Administração de Empresas, v. 49, n. 3, p. 266-281, 2009.

Aprendizagem organizacional e as raízes de sua polissemia. In: ANTONELLO, C. S.; GODOY, A. S. (org.) Aprendizagem organizacional no Brasil. Porto Alegre: Bookman, 2011. p.31-50.

BOUD, D.; GARRICK, J. Understandings of workplace learning. In: GARRICK, J. Informal Learning in the Workplace: Unmasking Human Resource Development. London: Routledge, 1998. p.1-11. 
A produção sobre aprendizagem informal nas organizações no Brasil: mapeando o terreno e rastreando possibilidades futuras

CONLON, T. J. A review of informal learning literature, theory and implications for practice in developing global professional competence. Journal of European Industrial Training, v. 28 n. 2-4, p. 283-295, 2004.

CRESWELL, J. W. Projeto de pesquisa: métodos qualitativo, quantitativo e misto. 2. ed. Porto Alegre: Artmed, 2007.

CUNNINGHAM, J.; HILLIER, E. Informal learning in the workplace: key activities and processes. Education and Training.v.55, n.1, p. 37-51, 2013.

DAY, N. . Informal learning gets results. Workforce, v. 77, n. 6,p.30-36, 1988.

EASTERBY-SMITH, M.; BURGOYNE, J.; ARAuJO, L. (Org.) Aprendizagem

Organizacional e Organização de Aprendizagem: desenvolvimento na teoria e na prática. São Paulo: Atlas, 2001.

ELKJAER, B. Em busca de uma teoria de aprendizagem social. In: EASTERBY-SMITH, M.; BURGOYNE, J.; ARAUJO, L. Aprendizagem organizacional e organização de aprendizagem: desenvolvimento na teoria e na prática. São Paulo: Atlas, 2001. p. 100-116.

ERAUT, M. Informal learning in the workplace. Studies in Continuing Education, v.26, n.2, p. 247-273, 2004.

Informal learning in the workplace: evidence on the real value of work-based

learning (WBL). Development and Learning in Organizations, v. 25, n. 5, p. 8-12, 2011.

GARRICK, J. Informal Learning in the Workplace: Unmasking Human Resource

Development. London: Routledge, 1998.

GEPHART, R. Paradigmas and research methods. Research Methods Forum, v. 4, summer 1999. Disponível em division.aomonline.org/rm/1999_RMD_Forum_Paradigms

_and_Research_Methods.htm. Acesso em 15mai. 2013.

GERBER, R. Learning and Knowing in Workplaces: how do people learn in their work. In: CASTLETON, G.; GERBER, R.; PILLAY, H. Improving workplace learning: emerging international perspectives. New York: Nova Science Publishers, 2006. p. 35-45.

GODOY, A. S.; ANTONELLO, C. S. Cartografia da Aprendizagem Organizacional no Brasil. In: ANTONELLO, C. S.; GODOY, A. S. (org.) Aprendizagem organizacional no REAd | Porto Alegre - Edição 80 - N 1 - janeiro/abril 2015 - p. 57-88 
Diogo Reatto \& Arilda Schmidt Godoy

Brasil. Porto Alegre: Bookman, 2011. p. 51-77.

GUBA, E.; LINCOLN, Y. S. Competing paradigms in qualitative research. In: DENZIN, N. K.; LINCOLN, Y. S. (ed.) Handbook of qualitative research. Thousand Oaks, CA: Sage, 1994. p. 105-117.

HAGER, P. Informal learning: everyday living. In: JAVIS, P.; WATTS, M. (org.) The Routledge International Handbook of Learning. USA: Routledge, 2012. p. 207-215.

LE CLUS, M. Informal Learning in the workplace: a review of the literature. Australian Journal of Adult Learning,v.51, n.2, p. 355-373, 2011.

LIVINGSTONE, D. W. Exploring the icebergs of adult learning: findings of the first Canadian Survey of Informal Learning Practices. Centre for the Study of Education and Work, OISE/University of Toronto. NALL Working Paper, v. 10, 2000.Disponívelem: http://hdl.handle.net/1807/2724

MARSICK, V. J.; WATKINS, K. E. Informal and Incidental Learning. New Directions for Adult and Continuing Education, v.89, p. 25-34, 2001.

V. J.; YATES, J. L. Informal Learning and Complex Problem Solving of Radiologic Technologists Transitioning to the Workplace. In: HOU, H. New Research on Knowledge Management Applications and Lesson Learned, Croatia: InTech, 2012. p. 171-194.

MALCOLM, J.; HODKINSON, P.; COLLEY, H. The interrelationships between informal and formal learning. Journal of Workplace Learning.v.15, n.7/8,p. 313-318. 2003.

MERRIAM, S. B. Qualitative research and case study applications in education. San Francisco: Jossey-Bass, 1998.

Qualitative research in practice: examples for discussion and analysis. San

Francisco: Jossey-Bass, 2002.

MEZIROW, J. Transformative Dimensions of Adult Learning. San Francisco: JosseyBass, 1991.

NORONHA, D. P; FERREIRA, S. M. S. P. Revisões de literatura. In: CAMPELLO, B. S; CONDÓN, B. V.; KREMER, J. M. (orgs.) Fontes de informação para pesquisadores e REAd | Porto Alegre - Edição 80 - N 1 - janeiro/abril 2015 - p. 57-88 
A produção sobre aprendizagem informal nas organizações no Brasil: mapeando o terreno e rastreando possibilidades futuras

profissionais. Belo Horizonte: UFMG, 2000. p.191-198.

SCHWANDT, T. A. Dictionary of qualitative inquiry. 2 ed. Thousand Oaks: CA, 2001.

WATKINS, K. E.; MARSICK, V. J. Towards a theory of informal and incidental learning in organizations. International Journal of Lifelong Education.v.11, n.4, p.287-300, 1992. 